\title{
Evidencias de la amplificación del espacio social de la exclusión social entre la población inmigrante: un análisis del caso español ${ }^{1}$
}

\author{
Nerea Zugasti \\ Universidad Pública de Navarra \\ <nerea.zugasti@unavarra.es>
}

\section{Patricia Azcona}

Universidad Pública de Navarra

\begin{abstract}
Artikulu honen asmoa da marraztea zer egoeratan dauden immigranteak 2008az geroztik Espainiako gizartea atsekabetu duen eta gizarte-mailan gaur egun oraindik ondorioak agertzen dituen krisiaren barruan. Testuak gizarteratze-baztertze dinamiken azterketarako funtsezkoak diren hiru eremutan jartzen du arreta: lana, osasuna eta bizitokia. Horretarako, beste hainbat iturriren artean, FOESSA Fundazioak 2007, 2009 eta 2013. urteetan gizarteratzeari eta gizarte-premiei buruz egindako hiru galdeketetara jo dugu. Era horretara, nabarmendu egiten dira immigranteen gizarteratzeereduak Espainian dituen anbibalentziak, gizartearazoak nabarmen aldatzen eta areagotzen ari diren garai honetan. Horrela, krisiaren aurretik ere biztanleriak oro har bizi zuen zaurgarritasun-egoera baino egoera larriagoa bizi duen gizarte-talde batek jasandako inboluzio-prozesua agertzen da.
\end{abstract}

\section{GAKO-HITZAK:}

Immigranteak, gizarteratzea, enplegua, etxebizitza, osasuna.
Este artículo pretende dibujar la situación de la población inmigrante en el escenario de crisis que ha afligido a la sociedad española desde 2008 y que todavía muestra sus efectos en el plano social. El texto se centra en tres esferas clave para el análisis de las dinámicas de integración-exclusión: la laboral, la sanitaria y la residencial. Para ello, se recurre, entre otras fuentes, a las tres encuestas sobre integración social y necesidades sociales de la Fundación FOESSA, realizadas en 2007, 2009 y 2013. De esta manera, se ponen de relevancia las ambivalencias del modelo de integración de la población inmigrante en España en un momento de clara transformación e intensificación de las problemáticas sociales. Se revela así el proceso involutivo sufrido por parte de un colectivo que, con anterioridad a la crisis, ya experimentaba situaciones de vulnerabilidad social en mayor medida que la población general.

\section{Palabras Clave:}

Población inmigrante, integración, empleo, vivienda, salud. 


\section{Introducción}

Este artículo pretende analizar la situación de la población inmigrante en España en términos de integración. Se analiza, para ello, un periodo, el comprendido entre 2007 y 2013 , de transformación y cuestionamiento de las bases sobre las que se había asentado el modelo de integración español (existencia de un mercado de trabajo con necesidad de ser reforzado en las posiciones laborales bajas de la escala ocupacional; facilidad en el acceso a sistemas universalistas, como el sanitario; y posibilidades de establecer, a medio plazo, itinerarios residenciales ascendentes). El recurso fundamental para tal fin son las tres encuestas sobre integración social y necesidades sociales de la Fundación FOESSA realizadas en 2007, 2009 y 2013. Se analizan también otras fuentes, como la Encuesta de Población Activa (EPA) o el Censo de Población y Vivienda, del Instituto Nacional de Estadística.

El foco de atención recae en lo que podemos definir como tres esferas clásicas de los estudios relativos a la inserción social de la población inmigrante: la laboral, la residencial y la sanitaria. A la luz de estas esferas, puede constarse el retroceso experimentado por parte de la población inmigrante. En materia laboral, el empeoramiento de las condiciones en las que se desarrolla el empleo se suma al ya conocido impacto brutal del desempleo en este grupo social. En materia residencial, una parte del colectivo extranjero se ha visto obligado a cambiar sus proyectos de acceso a la vivienda en propiedad. En materia sanitaria, el peor posicionamiento de la población inmigrante se manifiesta tanto en un mayor impacto de las medidas administrativas conducentes a racionalizar el gasto público como en una mayor desventaja en lo relativo a la provisión y acceso a aquellos recursos destinados a mejorar la salud.

Así, haciendo uso de una mirada retrospectiva, se puede constatar que si bien existe una proporción de personas inmigrantes que han conseguido sobrevivir en el actual contexto, la crisis ha venido a reforzar la situación ya de partida desfavorable del colectivo. Sectores anteriormente ubicados en la denominada zona de integración han vivenciado situaciones de precariedad económica y procesos de exclusión social. Por su parte, aquellos sectores vulnerables inmensos en este tipo de dinámicas en escenarios de bonanza han asistido a un agravamiento de su situación.

El posicionamiento de la población inmigrante con anterioridad a la crisis se entiende como clave, pues ha hecho posible el mayor desarrollo de caminos dirigidos hacia el espacio de la exclusión. Dicha situación de partida se ha caracterizado no sólo por la configuración como grupo de riesgo per se, sino por una relación con el Estado de bienestar basada en un modelo de integración dado. La población inmigrante se ha incorporado como beneficiaria al Estado de bienestar de manera más tardía y no lo ha hecho de forma plena. El modelo de integración español, que ha suscitado críticas desde que se implantó, ha evidenciado sus déficits con el desarrollo de la actual crisis socioeconómica, unos déficits que se traducen en la constatación de una mayor incidencia de la exclusión social sobre la población inmigrante.

\section{La situación respecto al empleo}

El estudio del efecto de la crisis sobre la población extranjera nos obliga a detenernos en el modelo migratorio adoptado en nuestro país, un modelo de fuerte componente laboral. La centralidad del empleo como pilar para la integración social ha llevado a que el estatus laboral de la población inmigrante en el mercado de trabajo explique en gran medida la situación del colectivo y las relaciones con su entorno. Este particular modelo, si bien ha propiciado importantes avances en términos de integración, presenta ahora sus déficits, que incrementan la fragilidad de un amplio colectivo de población extranjera. La alta tasa de desempleo entre el colectivo extranjero (12,3\% en el cuarto trimestre de 2007 , según la Encuesta de Población Activa [EPA]), que se observaba ya antes de la crisis, ha avanzado a un ritmo vertiginoso en los últimos años (hasta alcanzar el $36,6 \%$ en el cuarto trimestre de 2013 , según la EPA, más de 12 puntos superior a la de las personas de nacionalidad española).

Más allá de los ya conocidos datos sobre el desempleo, la EPA nos indica que la crisis no ha supuesto la aparición de nuevas tendencias en la integración en el mercado de trabajo de la población extranjera. Por el contrario, ha implicado una amplificación de situaciones ya existentes. Este colectivo ya debía hacer frente a dificultades en mayor medida que la población nacional, pero la crisis ha supuesto un aumento de la brecha existente con ésta.

En 2006, el 20,4\% de los hogares encabezados por una persona extranjera tenían alguna persona desempleada en el hogar, 6,4 puntos por encima de los nacionales. Esos hogares mostraban además mayores dificultades para acceder a empleos de calidad, en este caso medidos a través de la consecución de un empleo indefinido por uno de sus miembros $(48,3 \%$ en 2006). Los indicadores que dan cuenta de la combinación de situaciones de los miembros del hogar mostraban también el importante riesgo de exclusión social de estas familias. Los núcleos encabezados por personas extranjeras debían hacer frente al desempleo total familiar en mayor medida que los nacionales ya antes de la crisis, y se encontraban también con mayor frecuencia en situaciones sin ingresos.

En la misma línea, las encuestas sobre integración y necesidades sociales 2013 llevadas a cabo por la Fundación FOESSA nos muestran el empeoramiento de una situación ya de partida desfavorable para la población extranjera. Tanto es así que, en 2007, eran más, en términos proporcionales, los hogares extran- 
jeros con algún parado y sin formación ocupacional que los nacionales. Además, la población extranjera mostraba una situación algo peor que la nacional en indicadores como el desempleo total familiar, pero sin muchas divergencias. Sin embargo, eran menos frecuentes los hogares extranjeros sin ingresos y con el sustentador principal en desempleo de larga duración. Esta cuestión debe ligarse, además de a las posibles diferencias en las expectativas y valores de ambos grupos poblacionales, a la menor capacidad de negociación de la población extranjera, que aceptaba puestos no deseados por la población autóctona y que además tenía, en términos generales, unas redes de apoyo menos desarrolladas.

En 2013, y en el marco de la rebaja general del nivel por debajo del cual se considera un empleo como inadecuado, encontramos que la población extranjera muestra una situación de desventaja en todos los indicadores analizados (Tabla 1). La incidencia de cuestiones clave, como el paro de larga duración del sustentador principal, duplica a la de los nacionales. Es más, las cifras de evolución muestran una tendencia comparativamente más dañina entre el colectivo extranjero. Así, el desempleo total familiar, que da cuenta de situaciones en las que el riesgo del desempleo no puede distribuirse entre los miembros del hogar, se ha multiplicado por seis entre los hogares extranjeros en el periodo analizado.

Por un lado, no podemos obviar que la población extranjera ha sido protagonista de importantes logros en el mercado de trabajo. Así, en un periodo de crisis, estudios como el de Zugasti (2013a) constatan que el balance de pérdida de empleo entre salidas y reincorporaciones suponía un aumento de 2,3 puntos en los desempleados españoles y de 2,5 puntos en los extranjeros, una diferencia reducida. Asimismo, Laparra (2011) ha puesto de manifiesto la importancia de las trayectorias de movilidad positivas entre sectores. Los procesos de ascenso social que se han producido entre personas inmigrantes con perfiles sociales más asentados deben también tenerse en cuenta.
Por otro lado, debemos señalar que la población inmigrante ha cumplido un papel importante de amortiguador en un mercado de trabajo que durante años ha pedido ser alimentado por sus posiciones bajas, por puestos vulnerables a la destrucción de empleo (Zugasti, 2014). De esta forma, la desventaja de los inmigrantes también puede ser explicada por su sobrerrepresentación en el segmento secundario del mercado de trabajo en tiempos de crisis. Tanto es así que, según los datos de las encuestas FOESSA, y a pesar de la destrucción de empleos no cualificados, ha aumentado la proporción de población inmigrante empleada en este tipo de puestos en casi 5 puntos, llegando a representar el $46 \%$ de los ocupados extranjeros. Cabe señalar que las encuestas FOESSA tienden a clasificar a más personas como no cualificada que otras fuentes como la Encuesta de Población Activa, pues la manera de medir la variable es diferente: aquí, hacemos referencia a las actividades del año anterior; en cambio, la EPA nos muestra las características del empleo desarrollado en la semana anterior a la realización de la encuesta, por lo que tiene una menor capacidad para detectar situaciones vinculadas a trabajos esporádicos y más precarios. Así, utilizando la EPA como fuente, Zugasti (2013b) señala que, en 2013, el 34,7\% de los extranjeros se empleaban en puestos no cualificados, cifra muy similar a la correspondiente al año anterior, 34,6\%.

Se observa también un importante cambio en lo que a la distribución por sectores se refiere. En este caso, la hipótesis de la existencia de trayectorias positivas hacia el sector servicios no parece ser la que toma fuerza, sino que más bien podemos decir que los cambios se deben a la concentración de la destrucción de empleo en sectores como el de la construcción. Cabe señalar, sin embargo, que el impacto de la crisis en los diferentes sectores altera también el panorama del empleo de la población inmigrante.

Asimismo y principalmente debido al importante descenso de trabajadores inmigrantes en el sector de la construcción, que, como vemos, ha afectado especialmente a la población extranjera, ha aumen-

Tabla 1. Incidencia de diferentes elementos vinculados al desempleo, por nacionalidad (\%) [2007 y 2013]

\begin{tabular}{|c|c|c|c|c|c|c|c|c|}
\hline & \multicolumn{4}{|c|}{ Personas } & \multicolumn{4}{|c|}{ Hogares } \\
\hline & \multicolumn{2}{|c|}{2007} & \multicolumn{2}{|c|}{2013} & \multicolumn{2}{|c|}{2007} & \multicolumn{2}{|c|}{2013} \\
\hline & $\begin{array}{c}\text { Nacionales y } \\
\text { UE15 }\end{array}$ & Extranjeros & $\begin{array}{c}\text { Nacionales y } \\
\text { UE15 }\end{array}$ & Extranjeros & $\begin{array}{c}\text { Nacionales y } \\
\text { UE15 }\end{array}$ & Extranjeros & $\begin{array}{l}\text { Nacionales y } \\
\text { UE15 }\end{array}$ & Extranjeros \\
\hline $\begin{array}{l}\text { Sustentador } \\
\text { principal } 12 \text { meses } \\
\text { o más parado }\end{array}$ & 1,2 & 0,1 & 8,4 & 17,1 & 1,1 & 0,3 & 6,8 & 13,9 \\
\hline $\begin{array}{l}\text { Hogares sin } \\
\text { ingresos }\end{array}$ & 4,8 & 3,9 & 7,3 & 11,2 & 5,0 & 4,1 & 7,4 & 11,7 \\
\hline $\begin{array}{l}\text { Hogares con } \\
\text { algún parado y } \\
\text { sin formación } \\
\text { ocupacional }\end{array}$ & 8,5 & 10,0 & 34,1 & 55,5 & 6,6 & 9,1 & 25,7 & 46,8 \\
\hline $\begin{array}{l}\text { Hogares con todos } \\
\text { los activos en } \\
\text { paro }\end{array}$ & 2,2 & 2,7 & 12,0 & 15,6 & 2,2 & 2,5 & 10,5 & 15,3 \\
\hline
\end{tabular}

Fuente: Encuestas FOESSA 2007 y 2013. 
tado también la proporción de personas empleadas en el sector servicios y en la agricultura. Esta última se encuentra caracterizada por la estacionalidad de las tareas y, en el caso de la población inmigrante, se ha vinculado a situaciones de fuerte desprotección en entornos de agricultura intensiva.

Debemos señalar también que las consecuencias de la destrucción de empleos temporales han afectado en mayor medida a la población extranjera. Así, la proporción de personas en este tipo de empleos ha pasado del $45,6 \%$ al $34,7 \%$, a la par que se han reducido las posibilidades de inserción en empleos sociales. Además, de la mano de una reducción general de los empleos de tipo irregular, ha bajado también la proporción de quienes trabajan en la economía informal.

En esta misma línea debemos señalar que, en 2013 , la población extranjera se emplea en mayor medida en jornadas ‘atípicas', tanto por exceso como por defecto de horas en relación a la jornada completa. Ha aumentado también la proporción de personas ocupadas en lo que pueden calificarse como 'empleos de exclusión', bien por la forma en la que se organiza el empleo o por la desprotección que implica. Estamos asistiendo, por tanto, a la acumulación de precariedades en el colectivo inmigrante.

Asimismo, si utilizamos un indicador sintético para medir las situaciones de precariedad, observamos la fuerte presencia de ésta entre el colectivo extranjero. La aproximación a este fenómeno puede resultar complicada; es más, la forma de medirlo está sujeta a un importante debate. Nosotras hemos considerado como precario aquel empleo que cumple tres de las siguientes características:

- Produce unos ingresos de menos de siete euros la hora.

- No se desarrolla durante todo el año.

- No es cualificado.

- Se realiza bajo la fórmula de contrato temporal, de empleo social, o es un empleo informal.

Además de la acumulación, hemos tenido en cuenta ciertas situaciones que, por la gravedad de la desprotección en la que redundan, deben vincularse directamente a la precariedad:

- Ausencia de cobertura de la Seguridad Social.

- Ocupaciones marginales.

- Duración inferior a seis meses al año.

- Retribución menor de cuatro euros la hora.

Hacemos referencia además a las actividades del año anterior a la realización de la encuesta. Cabe recordar, sin embargo, que esta operacionalización está sujeta a discusión y que otras fórmulas pueden dar lugar a diferentes niveles de empleo precario. Más allá del relevante debate sobre la medición de la calidad del empleo, y teniendo en cuenta la limitación de nuestra propuesta, relacionada con las posibilidades que nos ofrece una encuesta concreta, nos interesa mostrar las tendencias en términos de evolución por nacionalidad (Tabla 2 ).

Podemos afirmar entonces que el empleo en situación de precariedad se encuentra ampliamente extendido entre la población extranjera. Sin embargo, con el avance de la crisis se ha reducido la proporción de población extranjera empleada en este tipo de puestos. Esto no debe relacionarse con una mejora de sus condiciones de empleo, sino con un desigual impacto de la crisis del empleo: son las personas inmigrantes empleadas en este tipo de puestos las que preferentemente han pasado a engrosar las listas del desempleo. Descubrimos así que, en 2013 , se encontraban en desempleo el 35,9\% de las personas extranjeras que el año anterior tenían un empleo precario. Esta cifra se encuentra muy por encima de la correspondiente a la población nacional (29,4\%). Asimismo, cabe señalar que son las personas africanas las que sufren la precariedad laboral en mayor medida (52,9\%).

Tabla 2. Población con empleo precario, por nacionalidad (\%) [2006 y 2012]

\begin{tabular}{|l|c|c|c|c|}
\hline \multirow{2}{*}{ Año } & \multirow{2}{*}{$\begin{array}{c}\text { Empleo } \\
\text { precario }\end{array}$} & \multicolumn{2}{|c|}{ Nacionalidad } & \multirow{2}{*}{ Total } \\
\cline { 3 - 4 } & Española o UE15 & Extranjera & \\
\hline \multirow{2}{*}{2006} & No & 81,1 & 44,2 & 76,3 \\
\cline { 2 - 4 } & Sí & 18,9 & 55,8 & 23,7 \\
\hline \multirow{2}{*}{2012} & No & 75,9 & 47,7 & 72,8 \\
\cline { 2 - 4 } & Sí & 24,1 & 52,3 & 27,2 \\
\hline
\end{tabular}

Fuente: Encuestas FOESSA 2007 y 2013.

Los datos vinculados a las condiciones de trabajo de la población extranjera nos permiten afirmar el desigual impacto social de la crisis sobre los diferentes grupos sociales. La crisis, aunque ha tenido un fuerte impacto laboral en términos generales, ha golpeado más fuerte al colectivo inmigrante y pone en riesgo muchos de los avances conseguidos en términos de integración en el empleo.

Con todo, la capacidad de resistencia de la población inmigrante es significativa y se traduce en el mantenimiento de más de la mitad de este colectivo en puestos cualificados, así como en una amplia mayoría empleada en situaciones de estabilidad (ya sean puestos indefinidos 0 , a pesar de las diferencias existentes, empleos por cuenta propia) [Tabla 3]. Además, precisamente en un momento de convulsión del mercado laboral, observamos que la mayoría de las personas inmigrantes se emplean en jornadas completas: el $54 \%$ están ocupadas en este tipo de puestos, dato que se aleja de la imagen atribuida a este grupo poblacional.

Las evidencias de la continuidad del asentamiento de la población inmigrante en el mercado laboral quedan, sin embargo, empañadas por el proceso de deterioro de su relación con el mercado laboral y de las características de los puestos en los que se emplean. Los avances conseguidos están en peligro. 


\begin{tabular}{|c|c|c|c|c|c|}
\hline & & \multirow{2}{*}{\multicolumn{2}{|c|}{2007}} & \multirow{2}{*}{\multicolumn{2}{|c|}{2013}} \\
\hline & & & & & \\
\hline & & $\begin{array}{l}\text { Española } 0 \\
\text { UE15 }\end{array}$ & Extranjera & $\begin{array}{l}\text { Española o } \\
\text { UE15 }\end{array}$ & Extranjera \\
\hline \multirow{2}{*}{$\begin{array}{l}\text { Empleo en } \\
\text { exclusión }\end{array}$} & No & 93,4 & 69,6 & 91,6 & 67,4 \\
\hline & Sí & 6,6 & 30,4 & 8,4 & 32,6 \\
\hline \multirow{10}{*}{ Ocupación } & Fuerzas Armadas & 0,1 & - & 0,9 & - \\
\hline & Directores y gerentes & 6,9 & 1,4 & 4,2 & 1,0 \\
\hline & Técnicos y profesionales científicos e intelectuales & 11,9 & 5,2 & 14,5 & 2,6 \\
\hline & Técnicos y profesionales de apoyo & 13,2 & 1,3 & 10,9 & 2,6 \\
\hline & $\begin{array}{l}\text { Empleados contables y administrativos, y otros empleados de } \\
\text { oficina }\end{array}$ & 13,4 & 3,4 & 5,2 & 3,4 \\
\hline & $\begin{array}{l}\text { Trabajadores de los servicios de restauración, personales, } \\
\text { protección y vendedores }\end{array}$ & 18,3 & 21,0 & 24,1 & 25,0 \\
\hline & Trabajadores cualificados en el sector agrario y pesquero & 2,1 & 0,2 & 2,8 & 2,1 \\
\hline & $\begin{array}{l}\text { Artesanos y trabajadores cualificados de las industrias } \\
\text { manufactureras y la construcción }\end{array}$ & 13,8 & 25,3 & 12,9 & 9,4 \\
\hline & Operadores de instalaciones y maquinaria y montadores & 3,0 & 0,5 & 7,1 & 7,7 \\
\hline & Trabajadores no cualificados* & 17,3 & 41,6 & 17,2 & 46,0 \\
\hline \multirow{4}{*}{ Sector de actividad } & Agricultura & 3,9 & 4,5 & 5,2 & 12,3 \\
\hline & Industria & 9,0 & 4,9 & 9,7 & 7,7 \\
\hline & Construcción & 14,3 & 31,5 & 8,1 & 8,3 \\
\hline & Servicios & 72,8 & 59,1 & 77,0 & 71,6 \\
\hline \multirow{4}{*}{ Jornada laboral } & $<20$ horas & 5,4 & 6,9 & 6,8 & 8,9 \\
\hline & $20-36$ horas & 14,2 & 24,2 & 18,3 & 20,4 \\
\hline & $37-40$ horas & 66,1 & 55,5 & 59,7 & 54,1 \\
\hline & $>40$ horas & 14,3 & 13,4 & 15,2 & 16,6 \\
\hline \multirow{4}{*}{ Situación laboral } & Estable & 79,0 & 36,4 & 75,0 & 53,9 \\
\hline & Temporal & 19,6 & 45,6 & 21,2 & 34,7 \\
\hline & Empleo social & 0,2 & 2,3 & 0,6 & 0,3 \\
\hline & Irregularidad & 1,2 & 15,7 & 3,2 & 11,2 \\
\hline
\end{tabular}

* La denominación oficial ha pasado a ser 'ocupaciones elementales'.

Fuente: Encuestas FOESSA 2007 y 2013.

\section{La situación respecto a la vivienda}

La vivienda supone mucho más que el mero espacio físico: tiene el potencial de configurarse como un espacio relacional promotor del desarrollo integral y del proyecto vital de las personas. La vivienda debe entenderse entonces como un espacio social dentro de la esfera privada, determinante de la cobertura de múltiples necesidades que trascienden la referida al alojamiento. Es por ello por lo que el acceso a la vivienda y la calidad de ésta han sido objeto tradicional de las políticas sociales, ya sea a escala nacional como internacional.

Las variaciones en el ámbito de la vivienda que han caracterizado las últimas décadas han definido el panorama nacional a partir de los ciclos económicos vinculados a la esfera residencial, así como de la particular concepción de aquélla como reactivadora del empleo y de la economía. El olvido de la vertiente social de la vivienda, especialmente cuestionado durante este último periodo recesivo que ha sucedido a la etapa de apogeo anterior, ha ido de la mano del comportamiento mayoritario adoptado por los agentes económicos y las políticas públicas. Así, mientras que la apuesta por la extensión del parque inmobiliario y el fomento del régimen de vivienda en propiedad se han materializado a lo largo del territorio nacional, adoptando un papel clave en el acceso y en las formas de relación con la vivienda, las políticas sociales de vivienda han ocupado un lugar secundario.

Durante la época del denominado 'bum inmobiliario', José Manuel Naredo (2004) ya evidenciaba el impulso productivista al que en la sociedad española nos habíamos acogido, apuntando hacia la incongruencia entre la elevada proporción de viviendas y el número de personas que accedían a ellas. Un déficit en el acceso a la propiedad que, a su vez, se complementaba con el reducido espacio que el régimen de arrendamiento ocupaba dentro del parque inmobiliario español. 
Ahora, casi siete años después del estallido del bum inmobiliario, podemos observar los costes sociales de la política de vivienda predominante (y ausente de vertiente social), así como las nuevas formas de relación definitorias del escenario residencial español. De este modo, tras años de desarrollo de una crisis que se ha convertido en social, estamos asistiendo a los riesgos que pueden derivarse de la tenencia de una vivienda en propiedad con pagos pendientes. Estos riesgos derivados resultan especialmente relevantes para grupos vulnerables, como la población inmigrante.

También Jesús Leal (2005) se anticipaba en su distinción del impacto social de la política de vivienda. Así, antes de la materialización más evidente de las diferencias que la política de vivienda mayoritaria ha tenido entre grupos sociales, ya advertía sobre la presencia de una política de vivienda de impacto desigual, en la que las personas con más recursos encontraban sustanciales beneficios y aquellas económicamente vulnerables, como las personas extranjeras, tendían a quedarse en el camino en el intento de hacer efectivo el derecho a una vivienda digna. De este desigual impacto, se han derivado algunas casuísticas de exclusión residencial extrema, especialmente notorias entre la población inmigrante. Con todo, una parte de la población foránea ha conseguido equipararse con éxito a las pautas residenciales nacionales.

Profundizando en el régimen de tenencia, por ser la característica que, por definición, ha marcado el modelo residencial español, encontramos un acceso diferenciado en función de la nacionalidad (Tabla 4). Distinguimos entonces una mayor propensión hacia el alquiler entre la población extranjera, con claras diferencias por nacionalidad. Así, en 2007, el 69,3\% de los hogares extranjeros vivían en alquiler frente al 19,4\% de los españoles, y, en 2013 se registra un diferencial de 52,8 puntos entre los hogares extranjeros y españoles en cuanto al régimen de arrendamiento. No obstante, durante el periodo examinado (2007-2013) un cuarto de los hogares foráneos se sustentaban sobre una vivienda en propiedad, dato destacable particularmente al recordar lo reciente del asentamiento de la población extranjera, así como por la firmeza que otorga a dichos proyectos de asentamiento.

Tabla 4. Distribución de los hogares españoles y extranjeros, según el régimen de tenencia de vivienda (\%) [2007, 2009 y 2013]

\begin{tabular}{|c|c|c|c|c|}
\hline Nacionalidad & $\begin{array}{l}\text { Régimen de propiedad } \\
\text { de la vivienda }\end{array}$ & 2007 & 2009 & 2013 \\
\hline \multirow{3}{*}{$\begin{array}{l}\text { Población } \\
\text { española o UE15 }\end{array}$} & Propiedad & 78,1 & 79,5 & 78,7 \\
\hline & Alquiler & 19,4 & 18,6 & 19,6 \\
\hline & Otros & 2,5 & 1,9 & 1,7 \\
\hline \multirow{3}{*}{$\begin{array}{l}\text { Población } \\
\text { extracomunitaria } \\
\text { o UE12 }\end{array}$} & Propiedad & 26,0 & 24,6 & 25,5 \\
\hline & Alquiler & 69,3 & 74,0 & 72,4 \\
\hline & Otros & 4,7 & 1,4 & 2,1 \\
\hline
\end{tabular}

Fuente: Encuestas FOESSA 2007, 2009 y 2013.
Dado el predominio del régimen de tenencia de arrendamiento entre la población extranjera, resulta pertinente profundizar al respecto. Sin embargo, antes de examinar este asunto con más detalle, es oportuno recordar que debemos entender la tendencia hacia el alquiler partiendo de la ya constatada mayor incidencia de la precariedad laboral y del desempleo entre la población extranjera, la cual se vincula con su mayor presencia en las situaciones de carencia de ingresos (tasa de población en situación de bajos ingresos y de pobreza severa).

Así pues, en un primer momento debemos atender al desequilibrio entre la oferta de compra y el alquiler, que ha repercutido fundamentalmente en la población extranjera, debido a sus particulares características derivadas del proceso migratorio y vinculadas con el periodo inicial de especial inestabilidad:

La discriminación en el mercado de la vivienda permite, por un lado, alquilar a los inmigrantes cierto tipo de vivienda 'inalquilable' a los nativos, y por otro, favorece que el alquiler sea más alto para los inmigrantes de lo que se esperaría si el mercado no estuviera en una situación de desequilibrio. El desequilibrio en el mercado produce grandes rendimientos económicos (Martínez Veiga, 1999).

Los datos presentados por INE a través del Censo de Población y Vivienda nos acercan también a ese desequilibrio entre la oferta de viviendas de alquiler y de compra. En este sentido, el INE nos muestra que, de los 18.083.692 hogares registrados en 2011, el $78,9 \%$ contaban con una en propiedad, el $13,5 \%$ en alquiler y el 7,6\% en régimen de cesión. No obstante, pese a que los datos permiten comprender mejor el papel de la vivienda en propiedad en la sociedad española, la comparativa con el censo de 2001 muestra el aminoramiento en la conformación de hogares propietarios, al haber disminuido en 3,3 puntos porcentuales. En contraposición, el arrendamiento y la cesión aumentaron (en 2,1 y 1,1 puntos porcentuales respectivamente).

Al centrar la mirada en el alquiler social, nos topamos con una oferta aún más reducida. Eurostat nos muestra entonces que una comparativa europea sitúa al Estado español en una posición considerablemente por debajo de la media, ya que el parque social europeo era, en 2008 , del 8,7\%. En consecuencia, el acceso a un recurso tan escaso como el alquiler social no se ha correspondido con la demanda, sino con una oferta vinculada a la satisfacción normativa de una serie de requisitos formales y de necesidad establecidos para distribuirla.

En lo referido a las diferentes tipologías de arrendamiento existentes, si bien muchas no se corresponden con el nivel de aceptabilidad o con los modelos residenciales aspiracionales, se configuran a modo de estrategia residencial para los grupos más vulnerables. Así, tras realizar un breve examen del alquiler social, resulta apropiado reparar ahora en estas 
formas de tenencia alternativas que generalmente se establecen como refugio de la población extranjera más vulnerable. Hablamos de la coexistencia temporal, entre personas que no comparten vínculos de parentesco, en viviendas también habitualmente concebidas como temporales. Se trata de escenarios residenciales habitualmente asociados con el momento previo a la adquisición de una vivienda independiente, ya sea en propiedad o en régimen de arrendamiento. Pueden también configurarse, especialmente en el contexto actual, como el resultado de una trayectoria residencial descendente, de modo que resulta posible su estructuración como escenario posterior a una situación residencial favorable, consecuencia del empobrecimiento o el inicio de procesos de exclusión social.

La comparativa entre 2009 y 2013 (Tabla 5) nos presenta una fotografía similar, en la que la población extranjera se configura como principal usuaria de esta modalidad de vivienda compartida y alcanza, en 2013, al $12,2 \%$ de la población foránea. La distancia con la población nacional es evidente, ya que, en el mismo año, tan sólo el 1,5\% compartía piso con personas sin parentesco. No obstante, ambos grupos poblacionales presentan una tendencia ascendente al respecto, con un incremento de un $15,38 \%$ en el uso de esta fórmula por parte de la población nacional y de un 7,96\% en el caso de la extranjera. Así, aunque el incremento sufrido en este periodo fue superior en el caso de la población nacional, persiste una mayor adherencia de la población extranjera hacia esta fórmula, una adherencia sustentada sobre la necesidad.

Tabla 5. Hogares en los que hay personas que comparten piso con otras con las que no tienen ningún lazo de parentesco, por nacionalidad (\%) [2009 y 2013]

\begin{tabular}{|l|c|c|c|c|}
\cline { 2 - 5 } \multicolumn{1}{c|}{} & \multicolumn{2}{c|}{2009} & \multicolumn{2}{c|}{2013} \\
\cline { 2 - 5 } \multicolumn{1}{c|}{} & Sí & No & Si & No \\
\hline $\begin{array}{l}\text { Población española o } \\
\text { UE15 }\end{array}$ & 1,3 & 98,7 & 1,5 & 98,5 \\
\hline $\begin{array}{l}\text { Población } \\
\text { extracomunitaria o UE12 }\end{array}$ & 11,3 & 88,7 & 12,2 & 87,8 \\
\hline
\end{tabular}

Fuente: Encuesta FOESSA 2009 y 2013.
La fórmula residencial de compartir piso no sólo descansa sobre la nacionalidad, sino que también se encuentra estrechamente vinculada con el componente etario y el nivel de integración de los hogares. Si bien durante 2009 esta estrategia estaba presente en todos los hogares españoles ubicados en cualquier franja de edad y nivel de integración, los hogares integrados, así como aquellos encabezados por personas mayores de 30 años, no adoptaban dicha estrategia como alternativa frecuente. En contraposición, eran los hogares encabezados por personas menores de 30 años los que compartían piso en mayor medida (el 3,9\%). La situación de la población extranjera en dicho año difiere de la nacional, escenificando la distancia ya existente entre ambos colectivos. Pese a que entre los hogares extranjeros ésta era una situación más frecuente entre quienes se encontraban en la zona de exclusión, era también representativa de ciertos hogares integrados (el 7,4\% de los hogares extranjeros se acoge a esta fórmula frente al 1,2\% de los nacionales). Por su parte, en todas las franjas de edad existía un porcentaje considerable de hogares que compartían piso (Tabla 6), no concibiéndose dicha estrategia como exclusiva de las capas más jóvenes de la población. Si para el colectivo español esta fórmula estaba vinculada con el inicio de procesos de emancipación juvenil o con el desarrollo de estudios superiores fuera del territorio de residencia familiar, para el extranjero suponía una forma de residencia más, especialmente desplegada en hogares sustentados por personas de entre $30 \mathrm{y}$ 64 años (edad laboral). No obstante, se presupone igualmente para el colectivo extranjero como una estrategia vinculada a la fase de transición, a etapas concretas del proceso migratorio, aunque susceptible de prolongarse en ciertos momentos de especial vulnerabilidad, como el actual.

La aproximación a partir de los datos de 2013 permite observar, a la par que un incremento en cuanto a extensión de dicha estrategia en todos los grupos de edad, un ligero aumento entre los hogares excluidos, al tiempo que persiste una mayor incidencia entre los hogares extranjeros. El predominio de la estrategia de compartir piso se concentra nuevamente en la

Tabla 6. Hogares en los que hay personas que comparten piso con otras con las que no tienen ningún lazo de parentesco. Incidencia en función de las zonas de integración y de la franja etaria (\%) [2009 y 2013]

\begin{tabular}{|c|c|c|c|c|c|}
\hline & & \multicolumn{4}{|c|}{ Compartir piso con personas sin parentesco } \\
\hline & & \multicolumn{2}{|c|}{2009} & \multicolumn{2}{|c|}{2013} \\
\hline & & $\begin{array}{c}\text { Población española } \\
\text { o UE15 }\end{array}$ & $\begin{array}{c}\text { Población } \\
\text { extracomunitaria o } \\
\text { UE12 }\end{array}$ & $\begin{array}{c}\text { Población española } \\
\text { o UE15 }\end{array}$ & $\begin{array}{c}\text { Población } \\
\text { extracomunitaria o } \\
\text { UE12 }\end{array}$ \\
\hline \multirow{2}{*}{ Zonas de integración } & Integración & 1,2 & 7,4 & 1,1 & 7,9 \\
\hline & Exclusión & 2,0 & 15,7 & 3,2 & 16,8 \\
\hline \multirow{4}{*}{$\begin{array}{l}\text { Edad del sustentador } \\
\text { principal }\end{array}$} & $<30$ años & 3,9 & 8,8 & 3,9 & 19,7 \\
\hline & 30-44 años & 0,9 & 13,9 & 2,6 & 17,4 \\
\hline & 45-64 años & 1,2 & 12,2 & 1,3 & 11,8 \\
\hline & $\geq 65$ & 0,7 & 9,7 & 0,2 & 2,6 \\
\hline
\end{tabular}

Fuente: Encuestas FOESSA 2009 y 2013. 
zona relativa a la exclusión (donde el 16,8 \% de los hogares extranjeros y el 3,2 \% de los nacionales la adoptan) y en los hogares encabezados por menores de 30 años, lo que evidencia la 'aventajada' situación residencial de la tercera edad. Podemos decir entonces que la adopción de esta estrategia de residencia alternativa se concentra en el colectivo extranjero y se materializa en los grupos más vulnerables, como las personas excluidas.

Reparamos ahora en el subarriendo, por configurarse como otra de las estrategias en las que el colectivo extranjero ha tendido a refugiarse. Al sustentarse sobre una base puramente económica, el subarriendo tiene la capacidad de contribuir tanto al elevado precio que ha adquirido la vivienda en alquiler como al peor posicionamiento sociorresidencial de la población extranjera. Especialmente vulnerables resultan las situaciones ligadas a esta modalidad de residencia, por no derivarse de ella ningún derecho para las personas usuarias, lo que las coloca habitualmente en una situación de desprotección. Muestra de ello sería la imposibilidad de empadronarse en una vivienda de estas características.

La incidencia del subarriendo es, tal y como muestran los datos, mayor entre la población extranjera, de modo que mientras que el $1,6 \%$ de los hogares foráneos hacen uso de esta alternativa inmersa en el mercado inmobiliario secundario, no tenemos constancia de su adopción por parte de la población nacional. No obstante, debido a que esta modalidad residencial no resulta sencilla de detectar, los datos han de tomarse con cautela, presuponiendo una infrarrepresentación general de su uso. Por ende, si bien parece no ser la estrategia más frecuente para nadie, del examen de los datos vinculados a esta opción residencial se confirma una mayor preferencia por el subarriendo por parte de la población extranjera. En 2013, el 1,6\% de los hogares extranjeros se acogían a esta fórmula residencial, pero ningún hogar español lo hacía. Las situaciones de subarriendo son difícilmente detectables y es posible que la encuesta esté infrarrepresentando estas realidades. Aun así, podemos señalar que la población extranjera tiende a utilizar en mayor medida las alternativas que presenta el mercado inmobiliario secundario.

Con todo, debemos apuntar también los avances conseguidos en materia de integración residencial, dado que la tenencia en precario ${ }^{2}$ ha disminuido significativamente entre los hogares extranjeros, pasando del $17,3 \%$ en 2007 al 3,4\% en 2013 .

En suma, la relación de la población inmigrante con el ámbito residencial ha estado caracterizada por las conquistas progresivas, acercándose durante los años previos a la crisis a las pautas residenciales desarrolladas a escala nacional. Si bien no ha conse-

${ }^{2}$ Ubicamos en esta categoría a aquellos hogares que residen en viviendas facilitadas gratuitamente por otras personas o instituciones, realquiladas o fruto de la ocupación ilegal. guido equipararse completamente a las situaciones y procesos relacionados con la vivienda de la población española, la ha seguido de cerca. La aproximación de la población extranjera a las pautas residenciales nacionales ha de entenderse en términos dinámicos, procesuales, ya que ha tenido que recorrer el camino de acceso a la vivienda desde cero. La crisis ha supuesto, sin embargo, considerables retrocesos en el ámbito residencial para el colectivo inmigrante. Las vicisitudes vinculadas al ámbito residencial pueden suponer una importante regresión en materia de integración.

\section{La situación en el plano sanitario}

La salud se encuentra directamente vinculada con la calidad de vida de las personas y ejerce una importancia sustancial sobre las relaciones que éstas mantienen con su entorno social, así como con los ámbitos vinculados a la integración social, como el laboral o residencial. La salud tiene valor en sí misma, pero además tiene implicaciones sociales, siendo competencia de los poderes públicos la promoción y protección de la salud (Constitución Española, arts. 43.1 y 43.2).

Durante los últimos años, la relación de la población extranjera con respecto al Sistema Nacional de Salud ha variado de manera considerable con motivo del Real Decreto Ley 16/2012, de 20 de abril, de Medidas Urgentes para Garantizar la Sostenibilidad del Sistema Nacional de Salud y Mejorar la Calidad y Seguridad de sus Prestaciones. Esta medida legal, que afecta a las personas extranjeras en situación de irregularidad, se concibe como un retroceso respecto a la tendencia adoptada hasta la fecha en lo que a la integración sanitaria de la población no nacional se refiere. Con todo, el colectivo diana de dicha reforma no resulta representativo de la condición sanitaria de la población extranjera, aunque es innegable la aminoración sustancial en términos de derechos sanitarios que supone para la porción más vulnerable. El análisis que se realiza en este apartado se refiere al colectivo extracomunitario en exclusiva, debido a la cuestión administrativa que le aqueja y le distingue del resto de la sociedad.

Los argumentos que respaldaron la implantación del decreto ley que nos ocupa se sustentan sobre el presente escenario de escasez. El objetivo de racionalización que persigue esta medida no ha impedido, sin embargo, el surgimiento de debates sobre el posible impacto en términos de ruptura de la cohesión social y de acumulación de factores de riesgo entre la población vulnerable, así como en términos de la propia efectividad de la medida y, por supuesto, de la vulneración de derechos sociales básicos. Ya en 2008, un estudio realizado por la Fundación de Ciencias de la Salud, sobre las diferencias en la utilización de los servicios sanitarios entre la población inmigrante y la española (Regidor et al., 2008) advertía sobre el menor uso que la población inmigrante hace de los servicios sanitarios, especialmente en lo 
relativo a servicios especializados, medicina privada y servicios preventivos.

Cuando fijamos la mirada en 2013, la Encuesta FOESSA ya nos acerca hacia este proceso de pérdida de derechos sociales, mostrándonos una desprotección sanitaria del 3,2\% de la población extracomunitaria, concretada en la pérdida de la tarjeta sanitaria y materializada principalmente en la población de origen africano.

La privación sanitaria podemos observarla igualmente en el acceso de esta población a medicamentos y tratamientos. Mientras que el $7,4 \%$ de la población extracomunitaria manifiesta su incapacidad de adquirir medicinas y el 5,1\% señala haber abandonado tratamientos $\mathrm{y} / \mathrm{o}$ el uso de medicamentos por la imposibilidad de costearlos, el 4,4\% y el $2,9 \%$, respectivamente, del resto de la población manifiesta las mismas carencias. Dicho nivel de privación varía, sin embargo, según se formule la pregunta, ya que, tal y como muestra la Tabla 7, al interrogar sobre necesidades no cubiertas por razones económicas, el $37,5 \%$ de la población extranjera y el $16,9 \%$ del resto de la población señala, en 2013, necesitar tratamientos especializados, pero no poder asumir los costes derivados. En el caso de la población extranjera, este dato resulta 22,5 puntos porcentuales superior al recogido en $\mathbf{2 0 0 7}$, mientras que entre el resto de la población apenas ha variado, lo cual muestra la mayor incidencia de la dinámica mercantilista sobre este colectivo.

Las cotas de privación se incrementan para la sociedad de manera general; sin embargo, resulta revelador el menor acceso que la población extracomunitaria tiene a aquellos recursos sanitarios que requieren un desembolso económico. La insatisfacción o la satisfacción deficitaria de las necesidades propias del ámbito sanitario tendrán indudablemente consecuencias en el nivel de bienestar y cohesión social.

La Tabla 8 permite comparar datos entre 2007 y 2013, algo sumamente interesante, por vincular dos escenarios bien diferenciados. Así, 2007 muestra, para ambos grupos, niveles de privación sanitaria similares. Una lectura más detallada permite comprobar el peor posicionamiento de la población extracomunitaria durante el último año de bonanza. Los mayores niveles de privación para este colectivo son para tratamientos especializados, ingresos extra para el pago de gastos de hospitalización, comida o transporte, y servicios médicos privados, ítems en los que la distancia con la población comunitaria se hace

Tabla 7. Incidencia de las necesidades sanitarias no cubiertas, por nacionalidad (\%) [2013]

\begin{tabular}{|l|c|c|}
\cline { 2 - 3 } \multicolumn{1}{c|}{} & Población extracomunitaria & $\begin{array}{c}\text { Resto de la población (española, UE15, } \\
\text { UE12 ampliación, sin origen determinado) }\end{array}$ \\
\hline $\begin{array}{l}\text { Ha requerido atención médica y no ha acudido al } \\
\text { médico por no poder pagar el desplazamiento }\end{array}$ & 2,2 & 1,6 \\
\hline $\begin{array}{l}\text { Ha requerido atención médica y no ha acudido al } \\
\text { médico por estar en lista de espera }\end{array}$ & 2,6 & 3,6 \\
\hline $\begin{array}{l}\text { Ha dejado de comprar medicamentos que necesita } \\
\text { por no poder pagarlos }\end{array}$ & 7,4 & 4,4 \\
\hline $\begin{array}{l}\text { Ha dejado de comprar medicinas y/o seguir } \\
\text { tratamientos por no poder pagarlos }\end{array}$ & 5,1 & 2,9 \\
\hline
\end{tabular}

Fuente: Encuesta FOESSA 2013.

Tabla 8. Incidencia de las necesidades no cubiertas, por nacionalidad (\%) [2009 y 2013]

\begin{tabular}{|c|c|c|c|c|}
\hline & \multirow{2}{*}{\multicolumn{2}{|c|}{2007}} & \multirow{2}{*}{\multicolumn{2}{|c|}{2013}} \\
\hline & & & & \\
\hline & $\begin{array}{l}\text { Resto de la } \\
\text { población }\end{array}$ & $\begin{array}{l}\text { Población } \\
\text { extracomunitaria }\end{array}$ & $\begin{array}{l}\text { Resto de la } \\
\text { población }\end{array}$ & $\begin{array}{l}\text { Población } \\
\text { extracomunitaria }\end{array}$ \\
\hline Gafas & 5,9 & 5,7 & 11,3 & 24,8 \\
\hline Dentadura & 5,5 & 4,1 & 12,8 & 18,9 \\
\hline Muletas & 0,4 & 0,0 & 0,4 & 0,1 \\
\hline Prótesis & 0,7 & 0,8 & 0,6 & 0,3 \\
\hline Calzado ortopédico & 0,5 & 0,3 & 0,9 & 1,8 \\
\hline Silla de ruedas & 0,3 & 0,0 & 0,4 & 0,6 \\
\hline Coche adaptado & 0,4 & 0,2 & 0,3 & 1,7 \\
\hline Medicamentos & 1,2 & 1,3 & 3,3 & 3,4 \\
\hline Curas & 0,6 & 0,2 & 0,3 & 0,1 \\
\hline Rehabilitación & 1,2 & 0,2 & 1,5 & 1,2 \\
\hline Regímenes alimentarios & 1,3 & 0,5 & 1,0 & 0,4 \\
\hline Tratamientos especializados & 4,2 & 15,0 & 16,9 & 37,5 \\
\hline Servicios médicos privados & 1,5 & 9,1 & 3,3 & 4,2 \\
\hline Servicios médicos alternativos & 1,1 & 0,6 & 1,6 & 3,2 \\
\hline $\begin{array}{l}\text { Ingresos extra para el pago de gastos de hospitalización, comidas, } \\
\text { transporte... }\end{array}$ & 1,4 & 11,1 & 2,0 & 4,8 \\
\hline
\end{tabular}

Fuente: Encuestas FOESSA 2007 y 2013. 
evidente. Los datos de 2013 permiten constatar las repercusiones de los procesos de empobrecimiento monetario y de expansión de la exclusión, que siguen situando a la población extracomunitaria en clara desventaja. Es más, su situación ha empeorado comparativamente: si en 2007 las necesidades no cubiertas de esta población no superaban en todos los ítems analizados a los de la comunitaria, en 2013 lo hacen en todos, excepto en tres. Los ámbitos que en este nuevo contexto se caracterizan por una mayor carestía son los referidos a la necesidad de recibir tratamientos especializados, gafas y una dentadura adecuada.

Todo ello sugiere una tendencia descendente en la capacidad adquisitiva (en materia sanitaria) de la población extracomunitaria. El nivel de necesidades no cubiertas refleja entonces la mayor vulnerabilidad de este colectivo, y recuerda su configuración como grupo en riesgo de protagonizar procesos de exclusión social, que se materializa en niveles privativos preocupantes.

La privación también se ha extendido al ámbito alimentario, pieza clave para la salud (Tabla 9). Para el examen de las carencias alimentarias, recurrimos nuevamente a la división entre población extranjera y nacional que estructura el presente artículo. El motivo: la inexistencia de un vínculo directo entre la provisión alimentaria y la condición jurídico-administrativa.

El recurso al hambre nos muestra nuevamente un escenario en el que la población extranjera se encuentra peor posicionada. Así, en 2013 se presenta una desigual distribución del padecimiento de hambre: el $10,5 \%$ de los hogares extranjeros manifiesta experimentarlo, frente al $1,5 \%$ de la población española. La imposibilidad de llevar una dieta adecuada merece igualmente de atención. En este caso, si bien el dato de los hogares que declaran tal carencia es preocupante para ambos grupos poblacionales, sigue ubicando a la población extranjera nutricionalmente peor: durante 2013, el $11,6 \%$ de los hogares españoles no podían llevar una dieta adecuada, frente a casi un cuarto de los hogares extranjeros.

Tabla 9. Incidencia de la privación alimentaria en los hogares, por nacionalidad (\%) [2013]

\begin{tabular}{|l|c|c|}
\hline & $\begin{array}{c}\text { Población } \\
\text { española o UE15 }\end{array}$ & $\begin{array}{c}\text { Población } \\
\text { extracomunitaria } \\
\text { o UE12 }\end{array}$ \\
\hline $\begin{array}{l}\text { Hogares que pasan } \\
\text { hambre en la actualidad }\end{array}$ & 1,5 & 10,5 \\
\hline $\begin{array}{l}\text { Hogares que declaran } \\
\text { ser incapaces de llevar } \\
\text { una dieta adecuada }\end{array}$ & 11,6 & 24,5 \\
\hline
\end{tabular}

Fuente: Encuesta FOESSA 2013.

La comparativa entre ambos indicadores sanitarios muestra que la incapacidad de provisión de una dieta adecuada supera notablemente la imposibilidad de satisfacer el hambre. La principal razón radica en la facilidad de acallar al hambre resulta considerablemente mayor. Así, los hogares pueden llevar a cabo estrategias que les permitan satisfacer el hambre, pero no las necesidades alimentarias. Estas estrategias se fundan sobre la primacía del componente económico sobre el nutricional, y de ellas deriva la malnutrición, caracterizada por la ingesta de alimentos alejados de patrones saludables y, en general, con valores nutricionales prácticamente nulos 0 , cuanto menos, insuficientes.

Una mirada sociosanitaria nos ha permitido constatar la mayor vulnerabilidad de la población extranjera. La significativa reducción de las cotas de bienestar sanitario de este colectivo requiere entonces repensar el escenario sanitario actual en términos que trasciendan la mera racionalización del gasto público. Una lectura social de los retrocesos en materia sanitaria nos conduce así a la consideración de la necesidad de una atención sanitaria pública integradora y compensadora que sea garantía de igualdad de oportunidades y de cohesión social.

\section{Conclusiones}

A la luz de los datos examinados, se puede afirmar que el actual escenario de escasez ha supuesto un retroceso social en términos generales. Los avances en términos de integración que vinieron de la mano de la época de bonanza están dando paso a la intensificación de dinámicas exclusógenas presentes con anterioridad, así como a nuevas dinámicas asociadas a un contexto marcado por la vulnerabilidad. La crisis ha redundado en un aumento de las situaciones de necesidad y en la intensificación de procesos de exclusión.

Centrando la mirada en la población inmigrante, su trayectoria en materia de integración y asentamiento en la sociedad española resulta particularmente ambivalente. La recepción por parte de la sociedad española de la población inmigrante durante la época de bonanza se materializó en una acogida eminentemente laboral y a través de puestos definidos habitualmente como precarios. Sin embargo, fueron muchas las personas que consiguieron protagonizar itinerarios laborales positivos. Aun así, la presencia de un modelo de integración excesivamente centrado en el mercado no ha sido suficiente para mantener las situaciones de integración ante la llegada de una crisis de fuerte componente laboral.

Si bien hemos constatado que una parte importante de la población extranjera ha conseguido mantenerse en puestos de calidad (la mitad trabaja en puestos estables y de cierta cualificación), es necesario poner de manifiesto el impacto de la precariedad en el colectivo, que duplica al de la población nacional. Ello sucede a pesar de que se ha constatado una mayor destrucción de puestos precarios ocupados por personas extranjeras, que se suma a la mayor incidencia del desempleo en esta población. 
El alcance que el fenómeno migratorio adquirió durante las pasadas décadas se tradujo en la extensión del acceso a sistemas universalistas como el sanitario, lo que favoreció la integración. El proteccionismo público en el ámbito sanitario fue un punto clave en el entendimiento de las personas como sujetos de derecho. Partiendo de la Constitución Española (1978), “la protección de la salud (art. 43) se ha encuadrado en la situación de plena igualdad de derechos con los españoles" (Fernández Bernat, 2013) y contribuye así tanto a un adecuado nivel de bienestar sanitario como a la integración sociolaboral (debido a la fuerte correlación entre la salud y la integración laboral) y al otorgamiento de cierta solidez al modelo de integración español. De este modo, el Sistema Nacional de Salud no sólo no se estableció a modo de barrera simbólica, sino que promovió la integración de la población inmigrante a partir de su concepción como beneficiaria de derechos. Es ahora cuando las fronteras comienzan a erigirse a dicho respecto, materializándose en la pérdida del derecho a la tarjeta sanitaria de una porción que, si bien resulta minoritaria (el 3,2\% de la población extracomunitaria), evidencia el inicio del proceso de pérdida de derechos y, especialmente, la fragilidad del modelo de integración.

Por su parte, el asentamiento residencial de la población inmigrante fue igualmente favorable en términos generales, sin que se observen procesos globales de segregación acusados o definitorios de las pautas de acceso a la vivienda. La asimilación a las pautas adquiridas por la población española fue una constante en lo relativo al régimen de tenencia y derivó en un importante acceso a viviendas en propiedad. No obstante, el comportamiento de la población inmigrante ha variado respecto a la nacional y presenta dinámicas propias especialmente en el régimen de arrendamiento. De este modo, aunque ya en $2007 \mathrm{el}$ $26 \%$ de la población extranjera tenía una vivienda en propiedad (frente al $78,1 \%$ de la nacional), lo que constata una apuesta por la propiedad congruente con la predominante en el Estado español, las necesidades propias de su condición de migrantes derivaron en su refugio en el alquiler, donde tendieron a desarrollar estrategias diferenciales vinculadas con la fórmula de compartir piso (en 2013, el 12,2 \% de la población extranjera compartía piso con personas sin parentesco, frente al 1,5\% de la nacional).

Ahora, tras la llegada de la crisis, estamos asistiendo a la fragilidad del modelo de integración adoptado. La población inmigrante ha comenzado a desandar el camino avanzado durante la época de bonanza. A los elementos estructurales del mercado laboral, se suma la coyuntura socioeconómica y el repliegue de los sistemas de protección social, lo que hace necesario apelar a los mecanismos e instrumentos compensadores y promotores de la integración social. El curso que siga la población inmigrante en estas esferas resulta clave tanto para el desarrollo socioeconómico del Estado y de los propios hogares extranjeros como en términos de integración y cohesión social. En este marco, el establecimiento de un nuevo modelo de integración de la población inmigrante que aporte un mayor nivel de bienestar a través de la reducción de los desequilibrios sociales resulta inaplazable, y obligada la intervención de las políticas sociales en la atención a los nuevos problemas y necesidades. 
ESPAÑA (2012): “Real Decreto-Ley 16/2012, de 20 de abril, de Medidas Urgentes para Garantizar la Sostenibilidad del Sistema Nacional de Salud y Mejorar la Calidad y Seguridad de sus Prestaciones", Boletín Oficial del Estado, 24-4-2012, n-9 98, págs. 31.278-31.312.

- (1978): “Constitución Española”, Boletín Oficial del Estado, 29-12-1978, ํo-311, págs. 29.31329.424.

EUROSTAT ['http://epp.eurostat.ec.europa.eu/portal/page/ portal/eurostat/home/s, consultado el $14 \mathrm{de}$ mayo de 2014].

FERNÁNDEZ BERNAT, J. A. (2013): “Asistencia sanitaria e inmigración irregular”, Revista de Treball,

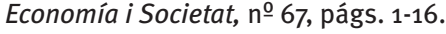

INSTITUTO NACIONAL DE ESTADÍSTICA (2011): Censos de Población y Vivienda 2011 [<http://www.ine.es/ censos2011_datos/cen11_datos_inicio.htm〉, consultado el 18 de mayo de 2014].

LAPARRA, M. (2011): "Immigration and social policy in Spain”, en GUILLÉN, A. M.; y LEÓN, M. (eds.): The Spanish Welfare State in European Context, Franham, Ashgate.

LEAL, J. (2005): "La política de vivienda en España", Documentación Social, $\mathrm{n}$ ํㅜ 138, págs. 63-80.

MARTíNEZ VEIGA, U. (1999): Pobreza, segregación y exclusión espacial. La vivienda de los inmigrantes extranjeros en España, Barcelona, Icaria.
NAREDO, J. M. (2004): "Perspectivas de la vivienda”, Información Económica Española, ํㅜ 815, págs. 143-154.

REGIDOR, E. et al. (2008): Diferencias en la utilización de los servicios sanitarios entre la población inmigrante y la población española, Madrid, Fundación de Ciencias de la Salud.

ZUGASTI, N. (2014): “Incidencia de la crisis en el empleo extranjero. Evidencias a partir de las transiciones laborales de trabajadores indefinidos", Papers. Revista de Sociología, vol. $99, \mathrm{n}^{0}$ 2, págs. 285-306.

- (2013a): “Cambios en la relación con la actividad laboral de la población extranjera en tiempos de crisis. Una lectura en términos de integración", Documentación Social, no - 170, págs. 161-189.

- (2013b): Transiciones laborales de la población inmigrante en época de crisis. Entre la integración y la exclusión en el mercado de trabajo, Madrid, Fundación FOESSA.

ZUGASTI, N.; AZCONA, P. (2014): Retrocesos en la integración de la población inmigrante. Evidencias de las limitaciones del modelo español, serie Documento de Trabajo del VII Informe sobre Exclusión y Desarrollo Social en España, no 3.4 , Madrid, Fundación Foessa; Cáritas Española. 